\title{
Metáfora orteguiana frente a símbolo zambraniano. Una divergencia
}

Palabras clave: metáfora, Ortega y Gasset, vectorialidad, símbolo, María Zambrano

\section{Introducción}

En una primera fase de su escritura (Horizonte de Liberalismo, 1930) María Zambrano $^{1}$, la conocida discípula de José Ortega y Gasset, compartió con él desde que se conocieran el interés por la metáfora, aunque fue desligándose de ese interés a medida que fue madurando y destilando sus propias visiones, más emparentadas con aspectos onírico-simbólicos que con figuras estrictamente metafóricas. El presente artículo no pretende profundizar en la filosofía de uno y otra, sino circunscribirse al plano estilístico, en particular al trato dado por Ortega y por Zambrano a un campo más estético y expresivo que filosófico: el de la imagen y la metáfora.

Las líneas de investigación iniciales de este análisis parten de dos hipótesis. La primera de ellas es la suposición que el imaginario metafórico Ortega y de Zambrano surgía de la propia tradición hispánica: un barroco tan perfilado, rico e influyente como el del Siglo de Oro español invitaba a presagiar dicha recepción como la más probable. La segunda apunta al origen extrahispánico de dicho imaginario, y en particular a la herencia antigua o grecolatina.

Habría que añadir además una tercera consideración, consistente en lo que Zambrano, en tanto que «discípula», término que la subordina a Ortega en tanto que receptora de ideas y estilo, recibe del imaginario de su maestro o

$1 \quad$ En los años veinte al coincidir en la Universidad Central de Madrid. 
preceptor, como cabría esperar de tal discipulado. Veremos que no solo la «tesis hispanista» ha de rendirse ante la evidencia de la recepción grecolatina en Ortega y presocrática (aunque no solo) en el caso de Zambrano. Y que en cuanto al tercer asunto, el de la recepción interpersonal, dicha recepción de Ortega en Zambrano puede aplicarse solo a una fase inicial y muy breve de la escritura zambraniana, y no así al resto de su peculiar producción de ensayos filosófico-literarios.

\section{La metáfora en Ortega}

Tomando como plataforma teórica de base los postulados de Ricoeur ( $L a$ métaphore vive, 1975), nos interesa sobre todo su concepto de tensión metafórica, pues según el autor francés, existe una «verdad metafórica» derivada de su propio carácter tensional entre semánticas incompatibles (Ricoeur, 2001: 335336). Seis decenios antes, Ortega (en Ensayo de estética a manera de prólogo, 1914) alude a dicha tensión en términos muy similares a los de Ricoeur, aunque sin llegar a las pretensiones sistematizadoras ni al despliegue teórico de Ricoeur ${ }^{2}$. En la obra citada Ricoeur ofrece todo un repaso de las teorías de la metáfora desde la Poética de Aristóteles hasta la segunda mitad del siglo XX, planteando la necesidad de abandonar la palabra como campo de acción de la metáfora para pasar al enunciado. Para una de las obras centrales del pensamiento zambraniano, El bombre y lo divino (1955), son de particular relevancia los estudios centrales de dicha obra, que tratan de las implicaciones de la metáfora con lo divino.

Tal y como exponía Senabre Sempere (en Lengua y estilo de Ortega y Gasset, 1964: 125-161) la metáfora más frecuente en Ortega es la atributiva, además de la impresionista y la aposicional. Pero más relevante aún que el tipo de metáfora son las imágenes que Ortega emplea, entre las que destacan las imágenes navales y marítimas, algo que también observa Senabre Sempere aunque no precisa su origen.

En Pidiendo un Goethe desde dentro (1932) Ortega ofrece una significativa metáfora: la «segunda navegación». Según apunta al inicio del prólogo Lasaga Medina (2014, I), dicha metáfora es acuñada por Ortega, pasando por alto, según parece y aunque nos pueda sorprender de un estudioso tan solvente, el origen del que procede dicha imagen, que está ni más ni menos en los diálogos de Platón, como por ejemplo en el Fedón:

2 La metáfora, habia escrito Ortega en dicho ensayo, consiste en lo que él denomina «desalejamiento» de ambos términos mediante la «des-realización» de uno (OO. CC. I, 2004: 675). 
[...] ¿quieres, Cebes, que te haga una exposición de mi segunda singladura en la búsqueda de la causa, en la que me ocupé?

-Desde luego que quiero más que nada - respondió.

- Me pareció entonces — dijo él-, después de eso, una vez que hube dejado de examinar las cosas, que debía precaverme para no sufrir lo que los que observan el sol durante un eclipse sufren en su observación. Pues algunos se echan a perder los ojos, a no ser que en el agua o en algún otro medio semejante contemplen la imagen del sol. Yo reflexioné entonces algo así y sentí temor de quedarme completamente ciego de alma al mirar directamente a las cosas con los ojos e intentar captarlas con todos mis sentidos. Opiné, pues, que era preciso refugiarme en los conceptos para examinar en ellos la verdad real (1988: 108-109)3.

Sin mencionar a Platón, sin embargo, Lasaga Medina menciona la «segunda singladura» de Ortega refiriéndose a la que sigue al primer viaje que había supuesto su pensamiento hasta 1930, año de su famosa aseveración Delenda est monarcbia, frase con la que Ortega concluyó el que fuera probablemente el más sonado y trascendental de sus artículos periodísticos, «El error Berenguer», publicado en el diario El Sol el 15 de noviembre de 1930, una proclama que habría sido además una suerte de reacción pública a la presión de María Zambrano a Ortega, puesto que la carta que ella había enviado unos meses antes a Ortega incidió decisivamente en una toma de postura abiertamente antimonárquica por parte de su profesor (Moreno Sanz, 2014, VI: 54).

Las metáforas más abundantes en Ortega son, junto a las procedentes del mundo náutico ${ }^{4}$, las relacionadas no tanto con una imagen concreta sino con una

3 Apunta Carlos García Gual en el mismo lugar que la expresión deúteros ploūs, «segunda navegación», alude a la que tiene que hacerse a fuerza de remos, a falta de viento propicio, $\mathrm{y}$, en otra acepción, al viaje menos perfecto y más seguro. La imagen del deúteros ploūs o segunda navegación aparece también en otros diálogos (Filebo, 19c; El político, 300c).

4 No se limita Ortega a usarlas en su escritura filosófica. En una intervención parlamentaria dos meses después de la proclamación de la Segunda República y ante la tarea de emprender la redacción conjunta de la Constitución del nuevo Estado, que se aprobaría en diciembre de 1931, Ortega se expresa, algo rebuscadamente para el contexto, en términos igualmente metafóricos: «se nos ha requisado [...] para venir aquí como un grupo de artesanos, que trae al hombro las alforjas con pensamientos, observaciones, estudios de largos años acerca del pasado de nuestro pueblo y su futuro, sobre temas jurídicos, pedagógicos, económicos, pensando si acaso de lo embutido en ellas podréis aprovechar algo para la enorme faena común. Hemos venido, pues, no por gusto, sino por deber; porque habíamos contribuido 
idea: la de vectorialidad, un elemento constante tanto en su prosa ensayística como en su actividad política. Veámoslo en dos ejemplos, el primero es de 1915 y el segundo de 1925:

En Castilla, mirar suele ser disparar la flecba visual al infinito; ni al salir de la pupila ni en el resto de su trayectoria encuentra obstáculo alguno. Cuando se ha hartado de volar en el vacío, la rauda saetilla cae por su propio peso y se hinca en un punto de la tierra que es ya casi un punto del cielo. En Castilla, la mirada crea y fija el horizonte (Notas de andar y ver, OO. CC., II: 384).

Para ver un objeto tenemos que acomodar de una cierta manera nuestro aparato ocular. Si nuestra acomodación visual es inadecuada, no veremos el objeto o lo veremos mal. Imagínese el lector que estamos mirando un jardín al través del vidrio de una ventana. Nuestros ojos se acomodarán de suerte que el rayo de la visión penetre el vidrio, sin detenerse en el, y vaya a prenderse en las flores y frondas. Como la meta de la visión es el jardín y hasta él va lanzado el rayo visual, no veremos el vidrio, pasará nuestra mirada a su través, sin percibirlo ( $\mathrm{La}$ deshumanización del arte, OO. CC., III: 851).

Desde luego, el primer ejemplo citado (mirar es disparar una flecha) la idea de vector que intentamos demostrar como rasgo general del estilo orteguiano es mucho más marcial y específica que en el segundo ejemplo, más ornamental y «ateneico» (el rayo de la visión). En el caso de la flecha, además, la asociación más inmediata es la de Zenón de Elea y su imagen de flecha móvil-inmóvil5. En cualquier caso, el imaginario al que recurre Ortega es a menudo eminentemente cinético-espacial, piensa en categorías de espacio, impulso y vectorialidad, e incluso cuando piensa en el paso del tiempo, es decir, en términos históricos o biográficos, lo hace echando mano de dicha vectorialización, algo que en realidad hace desde 1914, año de su trascendental obra Meditaciones del Quijote: «Pocas lecturas me han movido tanto como estas historias donde el héroe avanza raudo y recto, como un dardo, hacia una meta gloriosa» $(M Q$, OO.CC. I, 2004: 754).

[...] en embarcar a la nación nada menos que en un cambio de régimen, y no era bueno que mientras ella partía quedásemos nosotros en tierra» (OO. CC. IV, 2005: 792).

5 A una contradicción análoga se refiere Aristóteles en su Fisica (VI, 9, 239b 30) pues, paradójicamente, una flecha lanzada está quieta, pues aunque está en movimiento, el movimiento que describe está compuesto por infinitos momentos de inmovilidad, por lo que Zenón llegó a negar la posibilidad de que la flecha llegara nunca a su destino. 
También reaparece esta vectorialización en sus tempranas (y muy críticas) observaciones sobre la Segunda República; así, en una conferencia pronunciada en diciembre de 1931:

Como en el deporte es necesario un especial entrenamiento y hace falta seguir un régimen de vida, que mantenga el cuerpo en forma, [...] para hacer historia es menester que el ciudadano, el simple ciudadano, se halle moralmente en forma, tenso como un arco que va a disparar la flecba bacia lo alto. Sin eso no habrá nada. Y uno de los crímenes más insistentes de la monarquía fue el fomentar continuamente nuestra propensión a la chocarrería, al chiste envilecedor, a las ridículas disputas de casinillo («Rectificación de la República», OO. CC. IV, 2005: 839).

Si la metáfora, atendiendo a su simple sentido etimológico, puede simplificarse esquemáticamente como un movimiento de traslación o desplazamiento, también en la metáfora subyace implícito un vector que impulsa a un concepto a significar algo más, a dejar de significar lo anterior, o a ir dejando de significar cosas para asumir nuevas significaciones. ${ }^{6}$ Reviste por tanto particular interés que una de las variantes metafóricas más usadas por Ortega sea precisamente la vectorial. Una vectorialidad a la que en el caso del último ejemplo transcrito se le añade una componente espacial nueva: la de la elevación o movimiento ascendente (bacia lo alto, remacha Ortega en el ejemplo citado arriba). En esta circunstancia concreta de orador más que de intelectual, filósofo o ensayista, quiere aclarar que no hay que dejar de invertir todos los esfuerzos posibles por «elevar deportivamente» el nivel de la cosa pública que ahora representa la República por encima de las «bajezas» (chocarrería, vilezas, ridículas disputas de casinillo) que eran propias de la Monarquía7.

Asimismo, no hay que olvidar tampoco que en uno de sus textos más emblemáticos e influyentes, España invertebrada (1921), Ortega presenta España

6 Ortega teoriza sobre la metáfora en Ensayo de estética a manera de prólogo (OO. CC. I, 2004: 673), como ya se señaló más arriba.

7 Invevitablemente retumban aquí, con toda su orteguiana vectorialidad ascendente, las famosas palabras de Adolfo Suárez en plena Transición (9-6-1976) ante unas Cortes aún franquistas: «Vamos, sencillamente, a quitarle dramatismo a nuestra política. Vamos a elevar a la categoría política de normal lo que a nivel de calle es simplemente normal. Vamos a sentar las bases de un entendimiento duradero bajo el imperio de la ley». El contexto es bien distinto (bajeza de la dictadura de Primo y Berenguer frente a la elevación republicana en los años 30 y bajeza del franquismo frente a la elevación democrática en los 70) aunque la analogía, más que evidente. 
como «proyecto sugestivo de vida en común» (OO. CC. III, 2005: 442), y que por poco que nos detengamos a pensar sobre el término proyecto reaparecerá subyacente la idea de vector.

\section{La deriva simbolista de Zambrano}

Es la vectorialización ascendente la que constituye el nexo estilístico entre José Ortega y Gasset y María Zambrano. Lo «elevado» parece ocupar también en María Zambrano desde sus primeros escritos un lugar privilegiado. En una carta del 15 de diciembre de 1922 se expresa en los siguientes términos:

tenía la «Metafísica» de Averroes sobre la mesa y me dieron ganas de hojearla y he encontrado unas cosas muy nuevas para mí y q. sin comprenderlas del todo he encontrado en ellas un cierto aire de seriedad y de cosa elevada profunda y eso, elevada [...] porque le hacen poner a uno la inteligencia en cosas altas, muy por encima de las bajezas cotidianas; [...] ansia de conocimiento q. todos llevamos dentro, no hay cosa mejor, querido mío, que estos estudios filosóficos [...], lo más limpio de pasiones que el hombre ha hecho. [La Filosofía] es lo único respetable de las ciencias, lo q. prueba una fuerza intelectual superior en el hombre; la Filosofía entre todo es noble (Cartas a Gregorio del Campo, 2012: 69-70).

El momento culminante de la temprana recepción de la metafórica vectorial orteguiana en estas Cartas de Zambrano la encontramos el día de su 21 cumpleaños:

Nada hay que pueda detener a una flecha cuando se dispara; y yo be de seguir mi vida, no porque quiero deliberadamente, sino porque soy así y no puedo ser de otra manera. Tú ya sabes que yo necesito una vida activa, espiritual, por eso contra todos los obstáculos -que son muchos- sigo mi carrera (2012: 211).

El influjo estilístico orteguiano (o «huella metafórica») es fácilmente reconocible también desde su primer libro, publicado en 1930 y titulado Horizonte del liberalismo (1930). En otro escrito de la misma época, que anticipa lo que será un particular género al que Zambrano denominará «delirio», y titulado Ciudad ausente (1928), la pensadora se expresa con numerosos elementos del mundo metafórico orteguiano, donde aparecen con fuerza las imágenes navales y en concreto la idea del naufragio: «naufragaban en la niebla opalina torres 
y espadañas»; por otro lado aparece la vectorialización ascendente: «línea ascendente en ritmo de energía», así como la mirada y el paisaje: «la mirada que se hace ascética; el ojo no descansa en la cara amable de las cosas, es paisaje de inquietud que brinda lucha». La estudiosa de la obra zambraniana Goretti Ramírez, autora de la presentación, anejos y notas de los escritos autobiográficos, delirios y poemas de Zambrano (Ramírez, 2013: 129-190 y 1115-1429), afirma que cada uno de los delirios zambranianos avanzan hacia una fenomenología de los sueños, de la que este texto, publicado en la revista Manantial de Segovia en el verano de 1928, es una primera intuición, además de constituir un preludio de su célebre «razón poética», aunque Ramírez (2013: 1120) no especifica concretamente en qué. Intuimos, sin embargo, que el mecanismo de creación poética radica en el uso creciente de metáforas, imágenes y símbolos a partir de un punto de partida narrativo relativamente convencional.

Los títulos de Zambrano con una mayor repercusión, ya en los años 50, como El bombre y lo divino, Persona y democracia o Los sueños y el tiempo certifican que Zambrano abandona la metáfora y desarrolla un nuevo recurso, el símbolo, como queda patente en el uso y recurrencia palabras tan medulares como centro, esfinge, dintel o entrañas, a las que se les dedica particular atención. Aunque en El hombre y lo divino hay citas muy directas a Ortega y su uso de la metáfora, como por ejemplo: «Ortega y Gasset nos señalaba y describía sutilmente la situación de "naufragio" como la más humana de la vida humana, en sus cursos de "La razon vital"» (HD, OO. CC. III, 2005: 163); o bien «Ortega y Gasset decía que la vida humana es novela. Y novelar es más que proyectar; es inventarse, verse, ensoñarse» (HD, OO. CC. III, 2005: 196), lo cierto es que el nuevo aspecto estilístico de Zambrano en El bombre y lo divino es sin duda la aparición del símbolo. El naufragio que la discípula adopta de su maestro es el que siente el hombre racional ante una realidad que no es, que durante siglos había estado arraigada de diversas formas, pero que el «creyente de la razón» ya no capta, dejando despreciativamente la tarea al arte y la poesía, que sí puede hacer tangible por ejemplo lo monstruoso en aquello que ahora se etiqueta como fantasía:

Y así cada vez se sentía perdido, náufrago en una realidad extraña, irreductible, ante la cual quedaba desarmado, pues hay algo en la vida humana insobornable ante cualquier ensueño de la razón: ese fondo último del humano vivir que se llaman las entrañas y que son la sede del padecer. Al padecer solo pasajeramente puede engañársele (HD, OO. CC. III, 2005: 223). 
La reminiscencia de Goya es aquí muy posible. El ensueño de la razón evoca no ya metafóricamente sino más bien intertextual o intermedialmente al sueño de la razón goyesco, el que produce monstruos, es decir, el grabado 43 de la serie que Francisco de Goya realizó en 1799 bajo el titulo de Los caprichos. Es la ambigüedad del conocido emblema, en su interpretación (no ilustrada) de la razón como promotora de utopías monstruosas y truculentas reducciones racionalistas de la vida humana, la que a Zambrano interesa resaltar. Naufraga un nuevo tipo de hombre imbuido en exceso de arrogancia racional que desprecia y ningunea todo lo que no puede explicarse en los nuevos términos que la ideología de las Luces impone tras el XVIII, reduciendo, simplificando y nadificando.

Expone también María Zambrano en El bombre y lo divino su peculiar vision de la historia, haciendo uso de una recurrente metáfora pétrea, que ya es símbolo más que metáfora, la ruina: lo propiamente histórico, escribe Zambrano, no es ni el hecho resucitado con todos sus componentes - fantasma de su realidad-, ni tampoco la visión arbitraria que elude el hecho, sino la visión de los hechos en su supervivencia [...]. No los acontecimientos tal como fueron, sino lo que de ellos ha quedado: su ruina.

Las ruinas son lo más viviente de la historia, pues solo vive históricamente lo que ha sobrevivido a su destrucción, lo que ha quedado en ruinas. Y así, las ruinas nos darían el punto de identidad entre el vivir personal - entre la personal historiay la historia. Persona es lo que ha sobrevivido a la destrucción de todo en su vida y aun deja entrever que, de su propia vida, un sentido superior a los hechos les hace cobrar significación y conformarse en una imagen, la afirmación de una libertad imperecedera a través de la imposición de las circunstancias, en la cárcel de las situaciones (HD, OO. CC. III, 2005: 257).

Tomando como base estos tres breves párrafos ha de observarse en primer lugar el parentesco metafórico de la ruina con la imagen orteguiana del naufragio. En un segundo momento se asocia la imagen de la ruina con otras metáforas arquitectónicas o escultóricas (dintel, esfinges, monasterios, mausoleos, etc.), pero lo que realmente ocurre es que comienza a hacerse sumamente difícil seguir partiendo del presupuesto de que aquí quede ya rastro alguno de metaforicidad, pues el término sustituido ya no es una simple imagen, concepto o idea limitada a cumplir funciones retóricas o incluso llegando a producir sorpresa estética, sino que dicho término se desborda a sí mismo y se pasa ya a algo mucho más amplio. Zambrano condensa en el fragmento arriba citado 
nada más y nada menos que la historia, que además no es simplemente sustituida por una imagen que nos inspire un asombro que podamos ir interiorizando cognitivamente una vez desvanecido el extrañamiento inicial, desviviendo la metáfora (metáfora viva ricoeuriana), o lexicalizándola hasta llegar a aquello que Ricoeur llama metáfora muerta.

Nos parece que lo dicho en relación con la ruina tiene como consecuencia el deber de descartar, al menos en parte, la sospecha inicial de que Zambrano trate con metáforas, independientemente del debate sobre su origen (orteguiano, barroco, grecolatino o cualesquiera). Es el símbolo el que se alza como elemento central. Este nuevo enfoque toma mayor claridad contrastando la imagen que antes se mencionó, la del naufragio, con la de la ruina. El naufragio de la vida es una metáfora orteguiana de ecos platónicos, mientras que la ruina es un símbolo zambraniano. Resulta evidente que, en un plano semántico, el naufragio no pertenece al vivir en sí, aunque la vida pueda llevar a una sensación parecida y por ende aceptemos dicha metáfora como válida o inteligible, sin duda condicionados también por la tradición literaria occidental (Homero), mientras que la ruina es algo concreto, tangible, y víctima de lo que simboliza, que es el paso mismo del tiempo histórico.

Según Maria Luisa Maillard (1997), es probablemente la irracionalidad del símbolo, señalada desde muy diversos puntos de vista, la que ha llevado a filósofos como Ortega, Ricoeur y Wheelwright a desplazar su análisis, favoreciendo el de la metáfora, por ser el conocimiento de esta más aprehensible por la razón. Ortega, encastillado en su «razón vital», nunca habría querido abandonar el terreno seguro de la racionalidad, aun admitiendo el papel central de los sentimientos en la vida del hombre.

[...] no cabe duda de que la posibilidad de analizar lógicamente los mecanismos lingüísticos de la metáfora, al estar estos contenidos dentro del lenguaje, ha privilegiado su análisis por parte de los lingüistas, entendiéndola simplemente como una de las variantes de la polisemia, o intentando analizar los mecanismos formales que la diferencian de la metonimia como hace Le Guern. El estudio del símbolo, salvo el de aquellos autores próximos a la hermenéutica, ha quedado en manos de la antropología y la psicología (M. L. Maillard, 1997: 52).

Para Chantal Maillard, por su parte, la imagen simbólica requiere una intelectualización mediante la analogía. La metáfora funciona de otra manera, pues 
a la imagen metafórica le es suficiente con despertar la imaginación o la sensibilidad. En la relación simbólica nunca se interrumpe el enlace que existe entre el significante del término que simboliza y el elemento simbolizado. El símbolo, no así la metáfora, constituye una «representación analógica que mantiene viva la conciencia de que el término que simboliza es atribuido de manera ficticia al objeto simbolizado».

Los universos simbólicos se diferencian de los universos metafóricos en que estos superan la simple relación analógica. En la actividad simbólica no habría innovación a partir de la fusión de elementos analógicos, sino construcción de mapas equivalentes (Ch. Maillard, 1992: 114).

Los «universos metafóricos» son, en palabras de Chantal Maillard, innovaciones hechas a partir de una superposición de elementos o de modelos ya dados. En vez de proponer un modelo paralelo a los anteriores, se forma un modelo que los engloba y que pretende superarlos de forma indirecta o lateral. Los universos metafóricos son factores determinantes en una cultura, pero también suponen un peligro por la facilidad con que se les puede convertir en la única realidad posible (Ch. Maillard, 1992: 114). Esto ocurre a menudo cuando la metáfora se deteriora: «cuando mengua su actividad hasta que se paraliza y se transforma en concepto [...]», un peligro que «no es pernicioso siempre», dice Maillard, siempre que se entienda que dicha paralización corresponde a una «fase necesaria de la actividad comprensiva del hombre». Siempre y cuando no se le otorgue a la metáfora muerta valor de «verdad» (Ch. Mai1lard, 1992: 114-115). Es conveniente, por tanto, considerar la metáfora como núcleo del lenguaje tensivo y tratarla atendiendo a las características que, con fines descriptivos, podría atribuírsele a la realidad. Basta con que el lenguaje sea apto para expresar lo fáctico:

¿No son acaso los «hechos» un cúmulo de metáforas muertas? $\mathrm{Y}$, si nos bastara con expresar lo que nuestra cultura analítica entiende por fáctico, ¿no nos quedaríamos mudos frente a gran parte de las circunstancias vitales que no gozan [...] de naturaleza factual? (Ch. Maillard, 1992: 117)

Aclarada así pues la disparidad entre lo metafórico y lo simbólico, estamos en condiciones de enfrentarnos con mayor flexibilidad interpretativa a algunas de las más frecuentes imágenes (que no ya metáforas en el sentido orteguiano) zambranianas, como por ejemplo el templo. 
En la cuarta de las cinco partes de El bombre y lo divino, tanto el título como el primer subtítulo nos ofrecen ya una pista claramente emparentada con la ruina: «Los templos y la muerte en la antigua Grecia», seguido del subtítulo, «El templo y sus caminos»:

El carácter monumental que en algunos templos todavía resplandece, no se impone y debió de imponerse todavía menos en los tiempos en que su esplendor estaba intacto; [...] El templo todo en su recinto muestra a la vista algo, el mismo en su lugar - que los modernos llamamos paisaje- y una esencia o sustancia propia de la divinidad allí habitante, algo que al fin ha llegado a ser visible, a mostrarse por una acción humana, obediente a las leyes de lo divino (HD, OO. CC. III, 2005: 303).

Zambrano, tras abandonar la temática de las ruinas cuarenta páginas más atrás, nos devuelve a una reflexión que parte de la arquitectura, al estar relacionada con las ruinas metonímicamente, diríamos, pero sin hablar de la ruinas ni aun escribir esa palabra una sola vez. Se vale del templo para establecer una relación de contigüidad semántica, y seguir su reflexión por un derrotero ya más religioso y gradualmente alejado de lo arquitectónico:

Según se sabe, los templos, griegos o no, se han ido alzando sobre otros anteriores de la misma religión, y en algunos singulares casos dedicados a la misma advocación. Y a esta persistencia de lo sagrado dada en forma mínimamente sensible, corresponde la manifestación de las más veneradas manifestaciones de lo divino [...]. Y el templo es entonces la casa, la casa del hombre; no solo protectora, sino irradiante de vida propia. Una casa para el común de los hombres, no de todos los días. Una casa de excepción (HD, OO. CC. III, 2005: 307-308).

Se hilvana por tanto con la «casa excepcional» una - por ahora-triple idea, es decir, construida sobre la triada ruina-templo-casa, precisamente antes de entrar en una nueva cuestión de índole musical, la del ritmo. Este aspecto relaciona este pasaje con lo expuesto antes sobre Ortega, pues se trata de un ritmo que acompaña una vectorialidad inicialmente similar a la que veíamos antes en él, pero Zambrano enseguida marca su diferencia y precisa mediante la observación «el ir ya de una cierta manera según un ritmo», confiriendo prioridad al ritmo y la coreografía frente a la clara y escueta direccionalidad vectorial 
que favorece Ortega, es decir, el proceso cobra en Zambrano mayor importancia que el objetivo, pues, como ilustrativo ejemplo, ni siquiera se entra en los templos evocados por la pensadora sin las condiciones necesarias ( «santos pensamientos»), ritualidad que era en sí más relevante que su consecuencia o fin, y siempre acompañada de música y danza:

Las procesiones de Eleusis y del Partenón, la peregrinación al oráculo de Delfos marcan los momentos supremos de esta visita a la casa excepcional. El ir ya de una cierta manera según un ritmo, entonando los himnos propios de la divinidad [...] imponía ya una especie de conversión a causa de la palabra imperativa que el visitante encontraba grabada en el frontón del templo: «Nadie entra aquí si no es con santos pensamientos». $\mathrm{Y}$ así la entrevista con la figura de la divinidad celada en su cella era tan solo el momento culminante al que se accedía después de haber cumplido una serie de acciones rituales. Una suerte de danza, aunque danza aparente no hubiera; una melodía vivida aun sin canto ni música de instrumento alguno. [...] Teoría y danza, conocimiento. La razón se hacia sentir vivificando (HD, OO. CC. III, 2005: 308).

Por último habría que mencionar el dintel, cuarto símbolo arquitectónico zambraniano que relacionaría la recepción metafórico-simbólica de Ortega en Zambrano. Si la flecha orteguiana de la que se habló antes sugiere al lector la flecha veloz pero inmóvil de Zenón de Elea, la imagen del dintel es la que proporciona Parménides (también de Elea y maestro de Zenón) a María Zambrano. Puede constatarse en obras como Los sueños y el tiempo pero sobre todo el El bombre y lo divino, donde, en un contexto totalmente diferente presentado por la autora, el del final del Mundo Antiguo, se habla del «dintel mismo de la aparición del cristianismo» (HD, OO. CC. III, 2005: 291). Es decir, si bien el marco temático en el que se mueve la escritura de Zambrano se desvincula de Parménides ${ }^{8}$, la adopción del símbolo parmenidiano del dintel se preserva. Aunque aquí parezca que se fuerza una huella simbólica concreta, la continua mención del presocrático en El bombre y lo divino no hace más que confirmar dicha recepción.

8 En su célebre poema Peri physeos (I, 11-12) Parménides menciona el dintel de una puerta que da a dos sendas, la de la Noche y la del Día. 


\section{Conclusión}

La recepción metafórica orteguiana en Zambrano se limita a la obra de juventud de ésta. A pesar de las frecuentes menciones que de su admirado maestro hace en su obra, puede constatarse una evolución que se desentiende casi por completo de la metáfora, al caminar autónomamente hacia otra dimensión, la simbólica. El desarrollo de un concepto propio como es el de razón poética evidencia dicho distanciamiento del raciovitalismo orteguiano y de todo racionalismo en general. Entre Ortega y su forma de meditar sobre la técnica, sobre la ciencia, sobre la metáfora, en definitiva, siempre sobre algo, y Zambrano, cuyo pensamiento no es ya sobre temáticas concretas sino desde el interior de las mismas, hay una abismal diferencia que puede resumirse en pocos puntos:

En primer lugar, y como se ha visto, la evolución de la metáfora zambraniana diverge progresivamente de los primeros puntos en común con Ortega, es decir, metáfora como instrumento de pensamiento, o instrumentalización de la metáfora - de un estricto valor estilístico- para desembocar en campos de reflexión extrametafóricos.

En segundo lugar, la desconfianza de Ortega hacia la germinación y consolidación de una propia metaforicidad en Zambrano, en el momento en que ésta elabora y madura un estilo propio9. Esta habría sido la primera ruptura de Zambrano con su maestro, a finales de los años veinte. La instauración de la Segunda República supone un nuevo acercamiento a través del compromiso político, la ilusión que ambos tienen en el nuevo proyecto de regeneración pero también un nuevo alejamiento a raíz del temprano e inesperado silencio político de Ortega en 1932 ante lo que ve antes que casi nadie: la guerra civil, circunstancia radical de radical maniqueísmo en la que se produce el más grave desencuentro entre ambos. Aunque herida por los silencios y actitudes para ella incomprensibles, sigue admirándole, pero no ya imitándole. Ha encontrado una nueva senda de creación, relacionada con una peculiar elaboración de su experiencia en el exilio.

En tercer lugar, la muerte de Ortega en 1955 coincide con la publicación de $E l$ bombre y lo divino, que es algo más que un libro, pues hace de parteaguas entre la meditación sociopolítica y la entrada en una nueva fase de creación por la palabra, el inicio del apogeo de su razón poética. No es que la función de la metáfora evolucione, la propia naturaleza de la misma se pone en cuestión ante

9 Juan Fernando Ortega apunta al probable recelo por parte de José Ortega y Gasset ante una brillante alumna, a quien llega a rebajar públicamente con un comentario machista (J. F. Ortega, 1999). 
el hecho de que difícilmente puede hablarse ya de metaforicidad. El nuevo lenguaje que ha forjado la filósofa ya tiene un carácter de código simbólico, donde la palabra se inserta de manera pseudocodificada, en un proceso de generación poética de enorme dificultad. Lo hemos visto con el ejemplo concreto de «dintel», pero lo habríamos podido mostrar también con el de «aurora», «luz», «umbral», «centro» o «sangre», que no serían ya metáforas vivas en vías de lexicalización, sino algo así como cuerpos celestes o astros resemantizados que gravitan uno junto al otro en una galaxia semiótica personal. La experiencia de Zambrano con su lengua en su fase de madurez deviene así absolutamente ritual o cultual, alejándose superlativamente del pragmatismo y claridad cartesiana de su antiguo maestro.

Ortega, prototeorizador de la metáfora con anterioridad a Ricoeur, se limita a hablar de ella, de la metáfora, a veces en un tono verdaderamente lúdico, llegando a sospechar el lector que para seducir, y de hecho el lector acaba seducido. En Ortega el movimiento de significaciones tiende a ceder a las significaciones más estables, mientras que Zambrano, en un tono mucho más místico (influenciada no sólo por los místicos del Siglo de Oro, sino también por los sufíes del medioevo islámico), escribe desde el enigma. En ella el juego de «interpretabilidades» se hace flexible. Metaforiza hasta elaborar unos símbolos propios que luego pone a flotar cíclica y espiralmente, en busca de un conocimiento no racionalista. La estructura de su propia prosa ensayística se impregna de esta circularidad. Es a partir de El bombre y lo divino que podemos decir que lo que hay en Zambrano es estrictamente mito y símbolo. La metáfora se desvanece de su escritura. La lectura de sus obras requiere un grado de concentración y de relectura que sobrepasan cualquier consideración hermenéutica sobre el asunto. No hay tema. La escritura se sacraliza, pasando el objeto tematizado a un segundo plano. Se certifica con esto el fin de la recepción orteguiana y la emancipación o destilación de un estilo propio que ha llegado a tener su propia etiqueta, la de «razón poética». Todo bajo el deseo de reconciliar pensamiento y creación, tal y como Zambrano confiesa ya desde las primeras páginas de su «programática» obra Filosofía y poesía (1939). 


\section{Bibliografía}

Lasaga Medina, J. (2014): Ortega y Gasset. En torno a Galileo. Madrid: Biblioteca Nueva. Edición Digital / e-book.

Maillard, Ch. (1992): La creación por la metáfora. Introducción a la razón-poética. Barcelona: Anthropos.

Maillard García, M. L. (1997): María Zambrano: La literatura como conocimiento y participación. Lérida: Ensayos / Scriptura, Edicions de la Universitat de Lleida.

Moreno Sanz, (2014): Cronología de María Zambrano. En: Zambrano, M.: OO. CC., VI. Barcelona: Galaxia Gutenberg.

Ortega y Gasset, J. (2004) [1914]: Ensayo de estética a manera de prólogo (EEP). OO. CC., I. Madrid: Taurus.

Ortega y Gasset, J. (2004) [1914]: Meditaciones del Quijote (MQ). OO. CC., I. Madrid: Taurus. Ortega y Gasset, J. (2014 [1932]): En torno a Galileo (EG). Madrid: Ed. José Lasaga Medina. Biblioteca Nueva. Edición digital.

Ortega y Gasset, J. (2005) [1921]: España invertebrada. OO. CC., III. Madrid: Taurus.

Ortega y Gasset, J. (2005) [1931]) «Rectificación de la República», conferencia pronunciada el 6/12/1931 en el Cinema de la Ópera, Madrid. OO. CC., IV. Madrid: Taurus.

Ortega, J. F. (1999): «Ortega y Gasset se portó como un machista con María Zambrano». En: Diario El País. 10 de enero de 1999 (10/02/2016).

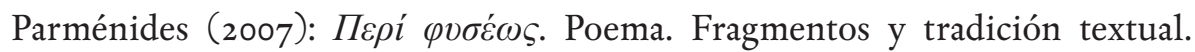
Madrid: Istmo.

Platón (1988): Diálogos III. Fedón. Banquete. Fedro. Madrid: Gredos.

Ramírez, G. (2014): Presentación Escritos autobiográficos. Delirios. Poemas (19281990). En: Zambrano, M., OO. CC., VI. Barcelona: Galaxia Gutenberg, pp. 129-190.

Ricoeur, P. (2001) [1975]: La métaphore vive. Paris: Seuil. Trad. esp. Neira, A.: La metáfora viva. Madrid: Cristiandad / Trotta.

Senabre Sempere, R. (1964), Lengua y estilo de Ortega y Gasset. Acta Salmanticensia, Universidad de Salamanca, Filosofía y Letras, tomo XVIII, núm. 3 .

Zambrano, M. (2012) [1922-1926]: Cartas inéditas (a Gregorio del Campo) $(C G C)$. Ed: Santiago Bolaños, M. F. Ourense: Linteo. 
Zambrano, M. (2015) [1939]: Filosofía y poesía. OO. CC., I. Barcelona: Galaxia Gutenberg.

Zambrano, M. (2015) [1930]: Horizonte del liberalismo (HL). OO. CC., I. Barcelona: Galaxia Gutenberg.

Zambrano, M. (2011) [1955]: El bombre y lo divino (HD). OO. CC., III. Barcelona: Galaxia Gutenberg. 
Alejandro Rodríguez Díaz del Real

University of Ljubljana

\section{Ortega's Metaphor versus Zambrano's Symbol. A Divergence.}

Keywords: metaphor, Ortega y Gasset, vectoriality, symbol, María Zambrano

There are great similarities and stylistic analogies between the essays and philosophical writings of José Ortega y Gasset (1883-1955) and María Zambrano (1904-1991), derived from the university relationship they had during the late 1920's, which can be seen in María Zambrano's respect and admiration towards Ortega y Gasset as her teacher. Taking the use of metaphor in María Zambrano's works as the starting point of this analysis, the present article explores the evolution of Zambrano's style, from a remarkable initial Ortegan influence in her very early writings to how she defines her own path, where the metaphor slowly disappears and the symbol becomes an increasingly central element of her literary expression. 
Alejandro Rodríguez Díaz del Real

Univerza v Ljubljani

\section{Metafora Ortega y Gasseta nasproti simbolu Maríe Zambrano. Divergenca}

Ključne besede: metafora, Ortega y Gasset, vektorialnost, simbol, María Zambrano

V esejističnem in filozofskem pisanju Joséja Ortega y Gasseta (1883-1955) in Maríe Zambrano (1904-1991) obstajajo velike podobnosti in slogovne analogije, ki izvirajo iz njunih univerzitetnih stikov ob koncu dvajsetih let 20. stoletja in iz »učenkinega« občudovanja učitelja. Članek na podlagi rabe metafore pri obeh avtorjih analizira razvoj in osamosvojitev Maríe Zambrano od začetnega Ortegovega vpliva v njenih zgodnjih besedilih do izoblikovanja in izčiščenja lastne poti, na kateri se metafora umakne simbolu kot osrednjemu elementu avtoričinega literarnega izraza. 